\title{
Commentary
}

\section{Designing Effective HIV Prevention Strategies for Female Street Sex Workers}

\author{
NABILA EL-BASSEL, D.S.W., and SUSAN WITTE, C.S.W.
}

$\mathbf{H}$ OMELESSNESS, RAPE, partner abuse and other violent events associated with psychological distress are common occurrences in the lives of street sex workers and have not been considered in their impact on developing HIV prevention programs. ${ }^{1-4}$ Feelings of stigmatization due to the nature and illegal status of the occupation are likely to contribute to significant psychological distress. ${ }^{5}$ Psychological distress and drug dependency may, in turn, undermine the motivation and ability of sex workers to adopt safer sex behavior. ${ }^{1,6,7}$ Most HIV programs targeted to this population tend to ignore the multiple factors that are associated with sex work. Mental health and other basic services such as drug abuse treatment, public assistance, housing, education, and training for alternative employment are not integrated into HIV prevention approaches. Moreover, most HIV prevention programs for female sex workers are not culturally sensitive and fail to involve sex workers in designing an intervention reflective of the community's unique needs or infrastructure. ${ }^{1}$

A review of the experiences and life-styles of low-income inner-city female sex workers depicts the critical needs of a comprehensive HIV treatment approach for these women. Recently, a study with 104 sex workers using both survey and in-depth interviews was completed by the Social Intervention Group at Columbia School of Social Work in collaboration with the Foundation for Research on Sexually Transmitted Diseases, Inc. (FROST'D). A mobile van outreach unit was used to both recruit participants and conduct the research (i.e., identify locations, conduct interviews, etc.) Within the general outreach program, the unit visits and identifies sex work "strolls" (locations) throughout New York City and is available 1 day per week at each location. Services include free condoms and prevention education, food, clothing, assistance in obtaining a social security card and in applying for government entitlements, and access to available drug treatment. The mobile van and its staff are seen as "friends," as a "lifeline," and as "a place to come home to." The services provided are appreciated within the sex worker community, and some women credit the unit with their success in practicing safer sex and admitting themselves to a detoxification program. However, many women also express concern that this type of service is "very limited" and does not go far enough" to promote and support a safe and effective transition to an alternate life-style that does not include prostitution, and it does not provide the knowledge and skills necessary to ensure that they will practice safer sex consistently.

To illustrate the needs of HIV services for these women, exerpts from in-depth interviews with two street sex workers are provided. The

Social Intervention Group, Columbia University School of Social Work, New York, NY. 
experiences of the first sex worker represent some of the barriers to achieving effective HIV prevention programs with this population. The experiences of the second woman illustrate a prevention success story and give voice to one sex worker's suggestions as to how effective HIV prevention strategies for this population can be designed and promoted.

\section{WHEN HIV PREVENTION FAILS-CASE HISTORY 1}

The following is an interview with a 50-yearold African-American woman who is a homeless crack abuser. She completed 2 years of technical school after high school and was last employed in 1985. Her sole support is through her sex work with occasional shoplifting of items from the local convenience store. Two grown children live on their own.

She has been exchanging sex for money for 27 years, and she reported sexual activity with as many as 10 partners a day, earning from $\$ 40$ to $\$ 50$ total. Her first sexual experience was traumatic-at 12 years of age she was raped by her stepfather. Over the past year, she has reported that she was raped once and physically assaulted twice during her sex work. She has been tested for HIV three times and was negative at her last testing. She was recently diagnosed with gonorrhea and reported having high blood pressure, asthma, and heart trouble.

If a customer offers more money or drugs she will usually agree to have sex without a condom. This is rationalized during the interview by saying that she "needs the money or drugs." Responding to questions about safer sex practices, this sex worker stated that although she has access to condoms, she only uses them occasionally for vaginal sex, and never uses them during oral sex.

When asked about additional service needs for women like herself, she explains:

I think I need more condoms, maybe, and more personal hygiene products, and be able to get into some of the detoxes without having to sign applications and wait so long. I would like more one-onone services. Also, it would help if the (outreach) staff would be able to escort us to the other programs we need.

When pressed for the ways that services for her might be more effective, she explained that a lack of continuity is very discouraging and makes her skeptical and mistrusting:

You know a lot of times people from programs say, "We gonna do this, we gonna do that." They come down one time and say, "Oh, we gonna have a meeting next week when so and so will come," and then next week it rains, so that person doesn't come. They tell us, "Oh, so and so couldn't make it so we can't have a meeting." And you all geared up and, you know, you feel like everybody's full of it.

\section{WHEN HIV PREVENTION WORKS-CASE HISTORY 2}

This sex worker is a 42-year-old Latina woman living with HIV. She claims to have a bachelor's degree in political science and business management and was last legitimately employed in a real estate office for a brief period in 1996. She has three grown children who live on their own. She reports that she does not receive any public assistance or entitlement benefits, and she supports herself through her sex work, by selling personal items, and from her lover's job. After struggling with a longterm alcohol and cocaine addiction, she was able to stop drinking with treatment at a suburban detoxification center. She currently attends Narcotics Anonymous (NA) on a weekly basis but has been unable to overcome her cocaine habit.

This sex worker reported being a street prostitute since the age of 16 , when she was raped and "turned out" by her father. She exchanges sex an average of 21 times per week with as many different partners, mostly for money rather than drugs. When she found out that she was infected with HIV, she began using male condoms for oral and vaginal sex, and even for hand jobs, with both her regular and commercial partners. She sees condom use as an important way for her to protect herself from sex- 
ually transmitted diseases and to prevent transmission of HIV to others. She had several bouts of syphilis and chlamydia in the past and credits the use of condoms in preventing any recent reinfections. Although "on the stroll" every day, whenever possible, she said she tries to explain to other sex workers why they need to use condoms, even when performing oral sex.

She offered during the interview an explanation as to why so many women on the street continue to practice unsafe sex when they know how to protect themselves:

Why do they still do it? Lack of using common sense because one side of their brain says to the other side, "Well, you don't really need to use 'em." Or the man says, "I'll go find somebody else." You gotta realize they have habits. They are desperate. They don't care about themselves. They want to hurt themselves. It's sick thinking and being sick and being desperate.

In order to have the prevention message register with sex workers, this sex worker believed that basic health needs must be addressed first:

Cause, see, it's not even just a matter of wearing a condom. It's a matter of personal hygiene. Its a matter of going for periodic medical or dental checkups because, if your system breaks down, anything can set in. You gotta take care of your body and your health.

Consistent safer sex practices may not be achieved until street sex workers have a reason to stay healthy. According to her this requires that sex workers have an opportunity to "feel like human beings" again. Multiple traumas, psychological distress, and stigmatization due to drug use, poverty, and prostitution leave these women with no sense of themselves and little self-worth. She reflects on her own experience in a rehabilitation center and describes what she believes is an important element to supporting health and sobriety first, and HIV prevention second:

And as soon as I got there, they said to me, "Would you like to have your hair done?" And I said, "Yeah!" I mean, I had$n^{\prime} t$ had my hair done in years and they had a little beauty parlor right there. And I got a pedicure and a manicure. And you know how I felt? Like, yeah, wow! Then, they gave me a key to my own room. And then, it was like being in college, we went out to the mess hall and got food. In one day's time, I was a whole different person. The next day when I woke up, I put a business suit on. I'll never forget that moment.

These women (street sex workers) need that. They will become human again, too. If I were in charge (of an HIV prevention program), I would focus my attention on how getting myself fixed up made me feel like a person again. It was like, I mean, you think, "Don't look back!" I think that's a very important first step. Then you ready for the next step.

Although current services for street sex workers are available to support basic needs and encourage safer sex by distributing condoms, the skill to make effective use of the helping resources is a talent that many of these women do not possess. Sustaining gains achieved with the assistance of helping resources requires an ability to work within the system.

Because the services here are fine. They help me 'cause I know how to take what they have and how to work it. Other people don't know how to ask. And you have to tell them to go back again until they get what they need, but they won't do that. They don't know how. They don't think they deserve it.

She asserts that HIV prevention may not be successful until the message is more broadly disseminated by peer leaders who are respected within the culture, and to whom the women may turn for help:

You have to get women, like that one over there in the red leather dress. She's a leader out here. Because nine out of 10 women out here are not going to listen to 
you (agency staff), you need to get them and make them the head "mommas." Instill it in their minds and make them, like, honorary members of the organization, to help infiltrate the masses. Because the masses think, "Oh, I use the condom. Ain't no problem." Yet, still they ride bareback giving the guy head, then jump in the saddle for the intercourse. I mean, forget about HIV, what about oral syphilis? They have to be educated and, at this point, they have to get strength from each other to do it.

That's how I would do it. I would first try to give them the message on my own. I would get one and we would work and push together for what has to be done. Then we both go get another one and go get another one and work it that way. Be exposed to the message, and then, one by one, get others to come on board.

When asked how to sustain prevention messages and safer sex practices, she described a need for women to feel like they are a part of something in which they feel pride and ownership:

Don't put no money in their hands, now. This is how it has to go. You have to bring their own ideas there (to the sex workers). Nobody is boss. You're working together. Everyone has some power and authority. This is like a bowl of fruit salad. The grapes are not gonna work without the mangos and watermelon. We all work together and get it going. If a large corporation doesn't work at upgrading their material, they go to bankruptcy court; just like if a husband and wife don't work on their relationship, they go to divorce court. So you gonna keep this prevention thing afloat and keep letting it rise, and you want to bring everybody to the top. How high? You don't know, you just want to go higher. When you know you are part of this, you made this, and your name is going to go up with it. Not I did it, but we did it? That's the only way. That's my feeling. But I know one thing, I never thought I could do it-that one day I would feel this way. The best way to reach these women is for a person like me to say, "Here's living proof that it can happen." Women like us need to help the designers of HIV programs make it fit our needs.

\section{DISCUSSION}

HIV prevention programs should consider how the high rates of crack use, rape, partner abuse, homelessness, and lack of mental health and drug services influence the sexual risk behaviors of sex workers. HIV programs for sex workers should integrate mental health and other basic services such as housing, public assistance, education, alternative employment training referrals, and drug treatment. In order to create culturally competent HIV prevention strategies, sex workers should be involved in the design and the delivery of the intervention.

Although not true for either of the above case histories, many women exchange sex for money in order to supplement their income from public assistance benefits. The need for improved HIV prevention strategies with sex workers is also underscored by the potential effects of welfare reform. Sex workers who are single adults without very young children may be unable to secure legitimate employment yet still be subject to time limits on receipt of public assistance benefits. As a result, they may find themselves having to increase their sex work in order to make ends meet.

Under welfare reform, lack of access to resources such as a Medicaid paid drug treatment program or public assistance and food stamps may put sex workers at higher risk for both HIV infection and drug use. One young female sex worker, who had been trading sex for money or drugs for 7 years expressed her ambivalence about testing HIV-negative by saying that if she had tested HIV-positive instead, she could get out of "working the street life" because she would be eligible for a variety of enhanced benefits provided through New York City's Division of AIDS Services. There may be a danger in that the message being sent to some poverty-stricken, noninfected adults is that there are advantages to being HIV-infected because better, more supportive 
services, especially larger cash grants, are available to those who are positive.

Public assistance and other services may help sex workers to live better lives and, for some, may enable them to leave or reduce sex trading. For those who are not willing or able to stop sex work, training to develop strategies to reduce the dangers of this occupation must be designed and delivered in a culturally competent manner.

\section{REFERENCES}

1. El-Bassel N, Schilling RF, Irwin KL, et al. Sex trading and psychological distress among women recruited from the streets of HarIem. Am J Public Health 1997;87 (1):66-70.

2. El-Bassel N, Gilbert L, Ivanoff A, Schilling RF, Borne D, Safyer SF. Correlates of crack abuse among incarcerated women: Psychological trauma, social support and coping behavior. Am J Drug Alcohol Abuse 1996;22:41-56.

3. Irwin $\mathrm{KL}$, Edlin BR, Wong $\mathrm{L}$, et al. Urban rape survivors: Characteristics and prevalence of human im- munodeficiency virus and other sexually transmitted infections. Obstet Gynecol 1995;85:330-336.

4. Edlin BR, Irwin KL, Faruque $S$, et al. Intersecting epidemics: Crack cocaine use and HIV infection among inner-city young adults. $\mathrm{N}$ Engl J Med 1994;331: 1422-1427.

5. Fullilove MT, Lown A, Fullilove RE. Crack "hos and skeezers": Traumatic experiences of women crack users. J Sex Res 1992;29:275-287.

6. Edlin BR, Irwin KL, Ludwig DD, et al. High-risk sex behavior among young street-recruited crack cocaine smokers in three American cities: An interim report. J Psychoactive Drugs 1992;24:363-371.

7. Wong L, Irwin K, Edlin B, Serrano Y, Evans P, McCoy $\mathrm{V}$. Risk factors of rape and prevalence of HIV and syphilis infection among rape victims in 3 cities. In abstracts of the 9th international conference of AIDS/Sexually Transmitted Diseases World Congress, Berlin, Germany, June 6-11, 1993. Abstract Po-CO2-2591.

Address reprint requests to: Nabila El-Bassel, D.S.W. Columbia University School of Social Work 622 W. 113th St. New York, NY 10025 